\title{
A Critical Review of Wire Electric DisCHARGE MACHINING
}

\author{
SINGH, B. \& MisRA, J. P.
}

Abstract: Wire electrical discharge machining (WEDM) is one of the most emerging non-conventional manufacturing processes for machining of difficult-to-machine materials. The aim of this book chapter is to present the consolidated information about the contributions of various researchers on WEDM process. This state of art review has been carried out to find out past research work on different materials, influence of process parameters on process performance characteristics and utilization of tools and techniques for correlating experimental results. In addition, this book chapter is concluded by highlighting the optimal ranges of parameters for various materials and indicating the future research directions which will provide a reference to machine tool operators and manufacturing industries depending upon their job requirements.

Key words: WEDM, material removal rate, kerf, surface integrity, optimization.
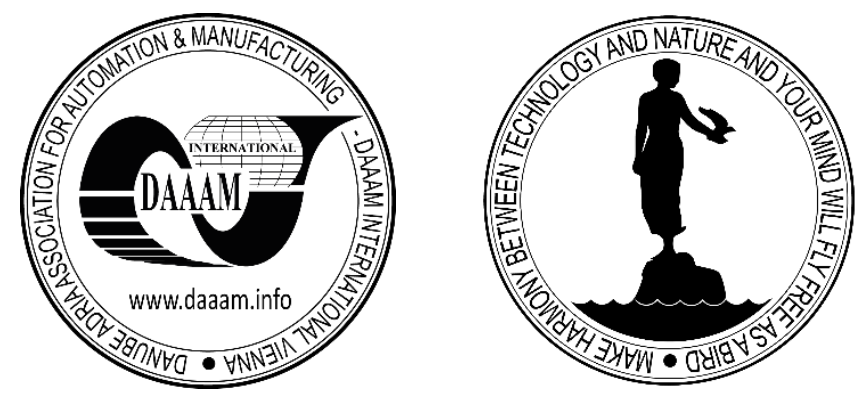

Authors' data: Singh, B[hupinder] \& Misra, J[oy] P[rakash], Mechanical Engineering Department, National Institute of Technology Kurukshetra, India, er.bsch@gmail.com

This Publication has to be referred as: Singh, B[hupinder] \& Misra, J[oy] P[rakash] (2016). A Critical Review of Wire Electric Discharge Machining, Chapter 23 in DAAAM International Scientific Book 2016, pp.249-266, B. Katalinic (Ed.), Published by DAAAM International, ISBN 978-3-902734-09-9, ISSN 1726-9687, Vienna, Austria

DOI:10.2507/daaam.scibook.2016.23 


\section{Introduction}

The development of aerospace, automobile, marine, nuclear reactors, missiles industries is accompanied with development of advance materials namely composites, ceramics and super alloys which are having high strength to weight ratio, high thermal conductivity, high corrosion resistance, high hardness properties. The precise processing of these materials using conventional machining techniques are found difficult and hence, it has become essential to develop cutting processes which can safely and conveniently machine such new materials with good productivity, surface finish and high accuracy. Wire electrical discharge machining (WEDM) is emerged to fill up this void. It is a highly precise, accurate, and widely accepted to manufacture components with intricate shapes and profiles. This technique is found advantageous in the field of automotive, aerospace, mould, tool and die industries, medical, optical, jewellery industry and dental parts processing. Owing to high processing capability, it is widely used in manufacturing of cam wheels, special gears, bearing cage, various press tools, dies, and similar intricate parts (Jain, 2002; Sarkar et al., 2005). Moreover, WEDM has been replacing other traditional machining operations in many industries throughout the world namely drilling, milling, grinding, turning, taper turning, etc.

\subsection{Wire Electric Discharge Machining (WEDM)}

It is a thermal erosion process in which material is removed by a series of sparks produced between an accurately positioned moving wire and workpiece. High frequency pulse of alternating or direct current is discharged from the wire to the workpiece with a very small spark gap through an insulated dielectric fluid. Many sparks can be observed at one time. This is because actual discharges can occur more than one hundred thousand times per second, with discharge sparks lasting in the range of 1/1,000,000 of a second or less. The volume of metal removed during this short period of spark discharge depends on the desired cutting speed and the surface finish required. Owing to electrical spark the temperature rises around $6000{ }^{\circ} \mathrm{C}$ resulting in vaporization and melting of workpiece; some of the wire material is also eroded away. The metal debris produced by the process is flushed away from the machining zone with a stream of dielectric fluid through the top and bottom flushing nozzles. The dielectric fluid also prevents the heating of workpiece. Without this cooling, thermal expansion of the part would affect size and positional accuracy. A DC or AC servo system is employed to maintain a gap $0.02-0.05 \mathrm{~mm}$ between the wire electrode and the workpiece and thus the servo mechanism prevents the shorting out by avoiding the contact of wire electrode and workpiece. As in WEDM the wire never touches the workpiece, it is a stress-free cutting operation. The wire electrode is usually a roll of brass, copper or brass and zinc wire from $0.05-0.30 \mathrm{~mm}$ in diameter. Sometimes molybdenum or tungsten wire is also used. New wire is constantly fed into the gap; these accounts for the extreme accuracy and repeatability of WEDM. A varying degree of taper ranging from $15^{\circ}$ for a $100 \mathrm{~mm}$ thick to $30^{\circ}$ for a $400 \mathrm{~mm}$ thick workpiece can be obtained on the cut surface using microprocessor control. An important number of $\mathrm{CNC}$ features, such as automatic threading of the wire and 
restarting the operation in the case of wire rupture, improve the performance of WEDM as a manufacturing process. Furthermore, it avoids wastages and rejections due to initial planning and checking of the program. Beside all these advantages, this process is also having some limitations (Benedict, 1987; Jain, 2002). WEDM is a thermal type advance machining process and the material is removed by fusion and vaporization. Therefore, the process has problem regarding the formation of recast layer. It has problem of wire breakage during machining of hard materials, powdered products, metal matrix composites, etc.

\section{Experimental Setup}

The experimental setup of WEDM consists of four major subsystems namely: (a) power supply system; (b) dielectric system; (c) positioning system; and (d) drive system. Power supply system contains DC high voltage transmission circuit, pulse main circuit and short protection circuit. Dielectric system consists of de-ionized water reservoir, filtration system, deionization system, and water chillier unit. The positioning system is made of two computerized numerical control tables. It operates in an adaptive control mode so that in case wire reaches closer to the workpiece, or the gap is bridged by debris and causes a short circuit, the positioning system is capable to sense it. Instantaneously, it will move back to re-establish proper cutting condition in the gap. The drive system assists in continuously driving the fresh wire, and always keeping the wire under suitable tension so that it moves in the machining zone as a straight wire. Moreover, it helps in minimizing wire break, taper, streaks as well as vibration marks. On the way while moving to the machining zone, wire is guided by sapphire or diamond wire guides. Schematic of WEDM process is shown in fig. 1.

\section{Process Parameters}

The process parameters of WEDM have been classified in four major groups: (a) electrode related parameters; (b) power supply related parameters; (c) dielectric related parameters; and (d) workpiece related parameters. The various input process parameters of WEDM and their inter-relationship is presented using Ishikawa's cause-effect diagram shown in fig. 2.

It is required in WEDM that the appropriate machining parameters are selected for an economical machining operation. The machining parameters can be set for optimum machining with the knowledge of the effect of the machining parameters on process performance characteristics of WEDM namely surface roughness, material removal rate, kerf width, wire wear ratio, and surface integrity aspects (e.g., white layer thickness, heat affected zone, and surface crack density). 
Singh, B. \& Misra, J. P.: A Critical Review of Wire Electric Discharge Machining

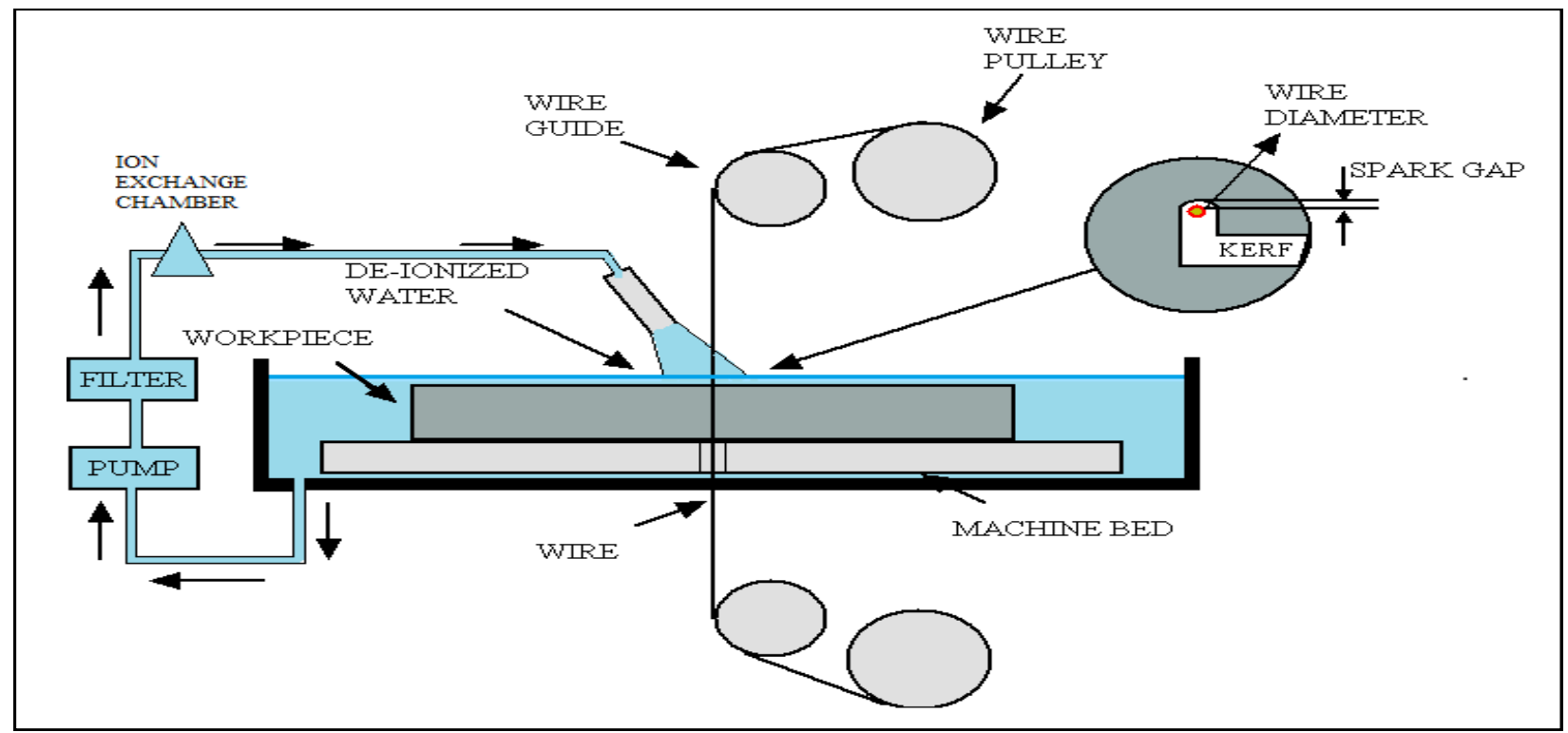

Fig.1. Schematic of WEDM process (Guitrau, 1997)

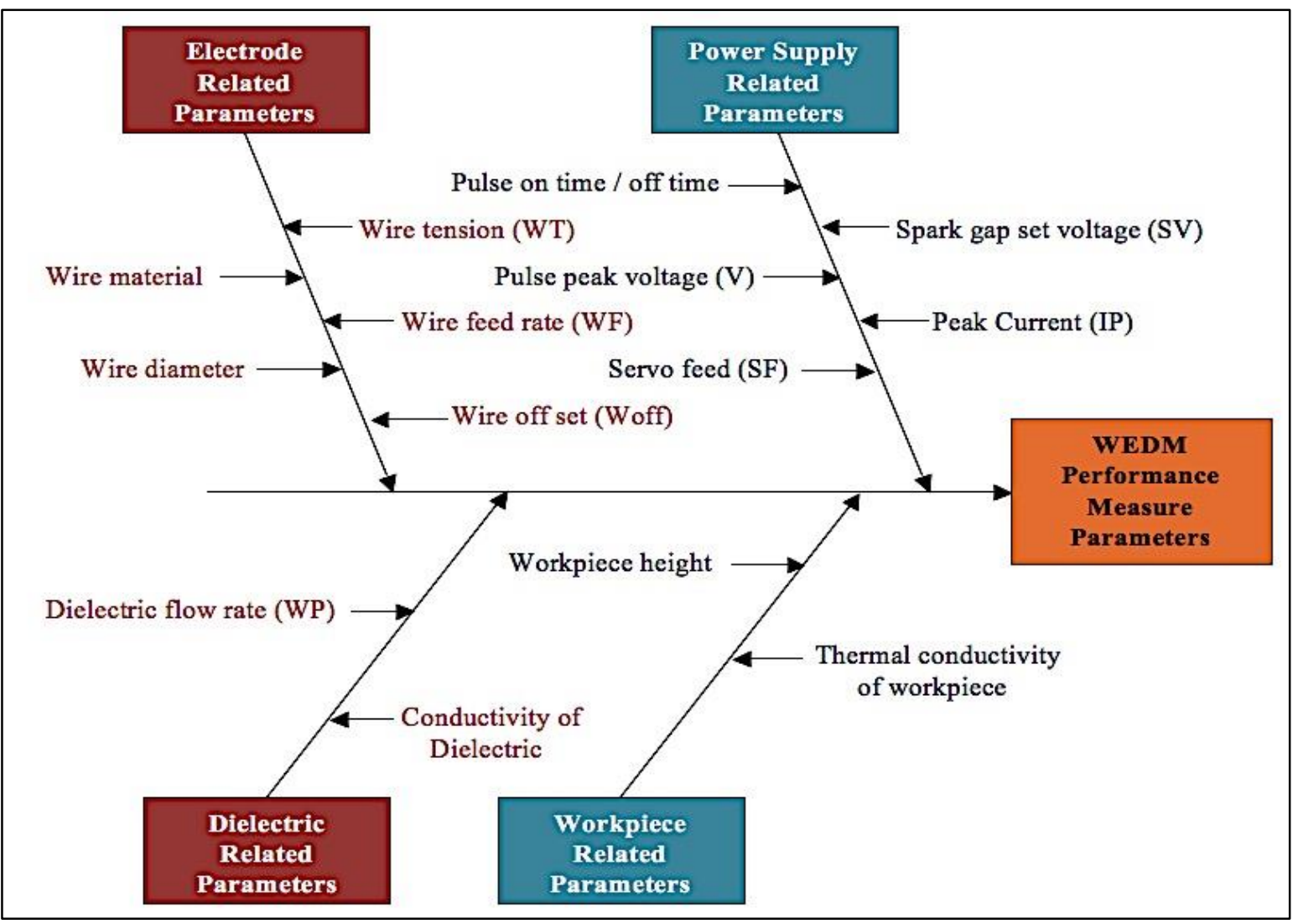

Fig. 2. Cause and effect diagram for WEDM process parameters

\section{Literature Review}

In the present scenario, WEDM is established as a crucial process in many industries, in which importance is given to variety, precision and accuracy. To the best knowledge of authors, this technique was first introduced to the manufacturing industry in the late 1960s. The development of the process was the result of seeking a technique to replace the machined electrode used in EDM. In 1974, Dulebohn applied 
the optical-line follower system to automatically control the shape of the component to be machined by the process. Towards the end of 1970s, when computer numerical control (CNC) system was integrated into WEDM that brought about a major evolution of the machining process. By 1975 the popularity of the technique was rapidly increased as the process and its capabilities were better understood by the industry (Benedict, 1987). Researchers have attempted to explore the process capability of this technique; however, the full potential utilization of this process is not absolutely solved because of its complex and stochastic nature and a large number of variables involved with the process. In this manuscript an attempt has been made to consolidate the information about the contributions of various researchers on WEDM process and to provide a guideline to the future users for enhancement of capability of the process. A brief outline of research works carried out so far is depicted in fig. 3 .

This process was introduced in late 1960s', and has revolutionized the tool and die, mould and metal working industries. This process is primarily employed for cutting operation (Spedding and Wang, 1997; Liao et al., 1997; Sarkar et al., 2005) though it is evident that the process is also utilized for turning and termed as wire electric discharge turning (WEDT) (Mohammadi et al., 2008; Haddad and Tehrani, 2008). Mohammadi et al. (2008) explored the effect of power supply, pulse-off time, servo voltage, wire tension, wire speed, rotational speed on surface roughness and roundness of machined part during WEDT of cemented steel of $10 \mathrm{~mm}$ diameter using $\mathrm{L}_{18}$ orthogonal array as design of experiments technique. It is evident that power has significant influence on surface roughness while, none of the factors have significant effect on roundness. Moreover, a regression model has been proposed for future researchers for proper selection of machining conditions. In 2015, Giridharan and Samuel tried WEDT process for EN24 and analysed the crater formation. It is obvious that most of the research work has dealt with vertical cutting (Sarkar et al., 2005; Sarkar et al., 2006; Haddad and Tehrani, 2008; Dabade and Karidkar, 2016) though WEDM taper cutting is also attempted. It is a very distinctive capability of WEDM process by which any drafted parts with different taper angles and different cross sections can be produced. Generally, all types of tools and dies are having some taper angle to avoid eventual part sticking and facilitate ejection although the application of WEDM process for taper cutting has not been significantly explored. Sanchez et al. (2008) predicted the angular error in WEDM taper cutting through experimental and numerical study on AISI D2 tool steel. Plaza et al. (2009) reported that the job thickness and the taper angle are the influencing factors for angular error. Since last decade, a number of hybrid machining processes (HMPs) are developed by combining advantage of WEDM with other machining techniques namely wire electrochemical grinding (WECG) and wire electrical discharge grinding (WEDG). WEDG is commonly used for the micro-machining of fine rods utilized in the electronic circuitry. In this technique, a rotary axis remains attached to WEDM to achieve higher material removal rate and to enable the generation of free-form cylindrical geometries. Masuzawa et al. (1985) carried out WEDG process to grind the rod with diameter less than $10 \mu \mathrm{m}$ without experienced operators. 
Singh, B. \& Misra, J. P.: A Critical Review of Wire Electric Discharge Machining

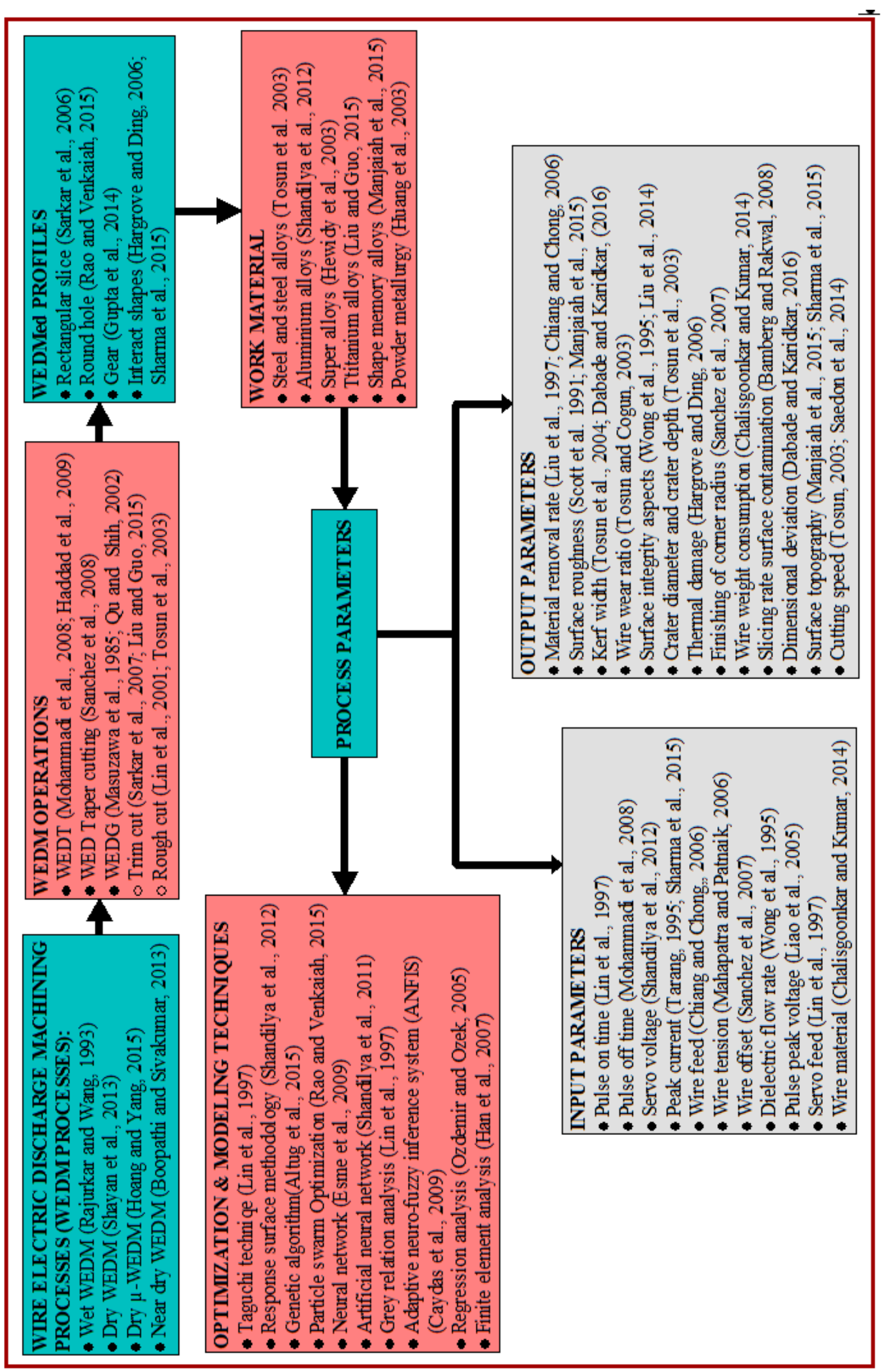

Fig. 3. A brief outline of past research works 
On the other hand, in recent past WECDM process is evolved out which replaces the electrical discharge used in WEDG by an electrochemical solution to produce high surface quality parts for a wide range of machining condition (Kuo et al., 2015). The effects of the various process parameters such as electrolyte, electrolyte flow rate, applied voltage, wire feed rate, machining time on surface integrity of the part produced have been investigated in the same feasibility study. In cutting operation WEDM primarily employed either for trim cut (Sarkar et al., 2006; Liu and Guo, 2015; Chalisgaonkar and Kumar, 2016) or rough cut (Tosun et al., 2003; Jangra et al. 2012; Boopathi and Sivakumar, 2013; Chalisgaonkar and Kumar, 2016). In 2010, Ali et al. utilized the technique for gear cutting and reported a comparative study of conventional and micro-WEDM technique on machining of meso/micro sized spur gear. In most recent work, Gupta et al., (2014) tried WEDM to produce miniature brass gears. It is evident from their study that the optimal setting of input process parameters namely servo voltage, pulse on time, pulse off time and wire feed rate minimizes the deviations in total profile and accumulated pitch.

In WEDM, material is removed owing to series of spark erosion in between wire tool and workpiece results in fusion and vaporization. This technique is suitable for producing any complicated shape in any conductive material regardless hardness of the material. To the best knowledge of authors, this technique can be successfully employed for machining of steel and steel alloys (Liao et. al., 1997; Spedding and Wang, 1997; Tosun and Cogun, 2003; Caydas et al., 2009; Boopathi and Sivakumar, 2013), aluminium and aluminium alloys (Thakur et al., 2016a, 2016b), titanium and its alloys (Nourbakhsh et al., 2013; Manjaiah et al., 2014; Chalisgaonkar and Kumar, 2016), super alloys (Goswami and Kumar, 2014; Dabade and Karidkar, 2016), metal matrix composites (Manna and Bhattacharyya, 2006; Shandilya et al., 2010), shape memory alloys (Manjaiah et al., 2014; Manjaiah et al., 2015), green compact manufactured by powder metallurgy (Hatami et al., 2012). A comparative study of published research work on WEDM is illustrated in fig. 3.

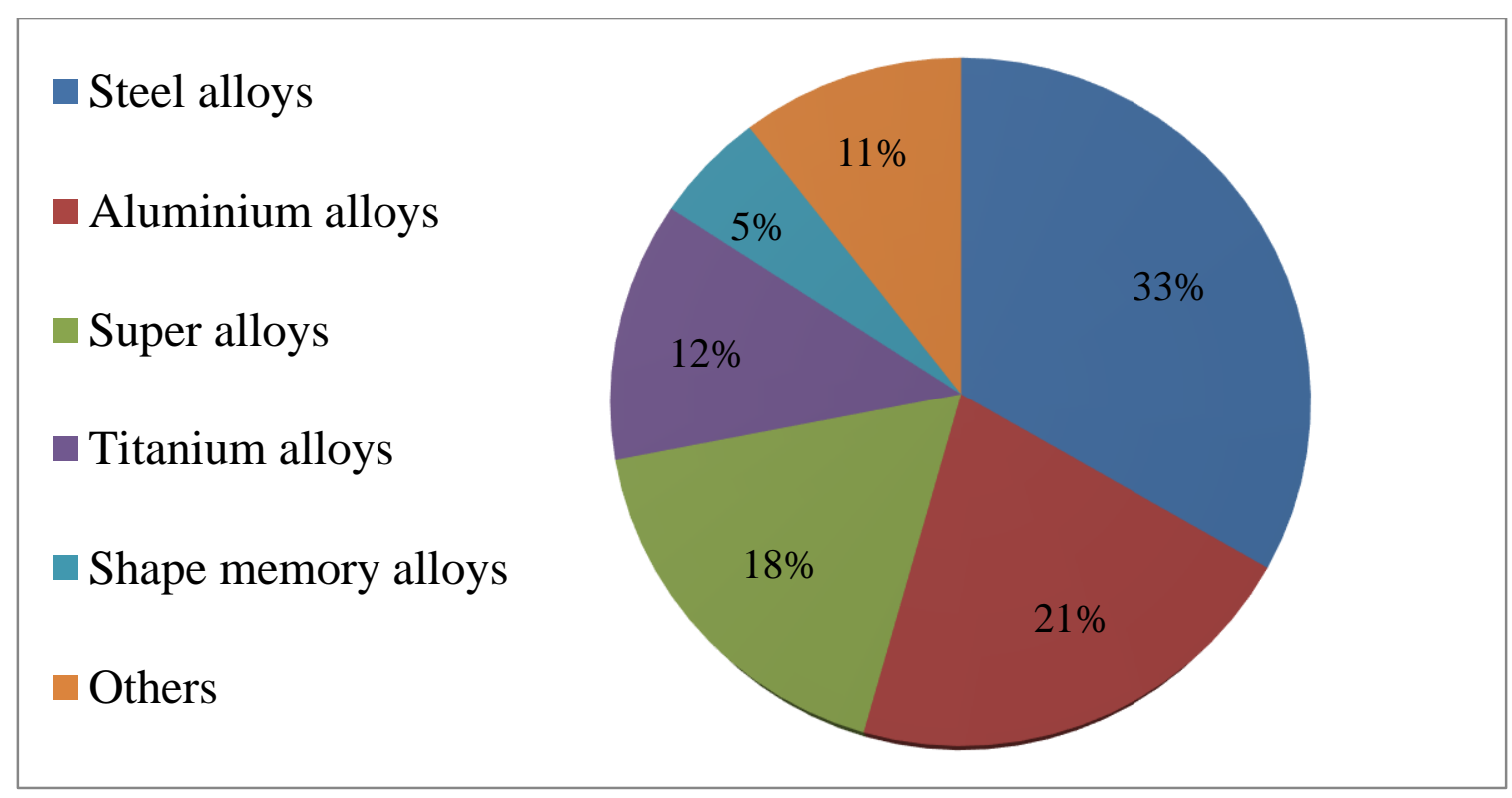

Fig. 3. Comparative study of published research work on WEDM 
In WEDM process pulse-on time $\left(\mathrm{T}_{\mathrm{on}}\right)$, pulse-off time $\left(\mathrm{T}_{\mathrm{off}}\right)$, servo voltage $(\mathrm{SV})$, peak current $\left(\mathrm{I}_{\mathrm{p}}\right)$, wire feed rate $(\mathrm{WF})$, wire tension $(\mathrm{WT})$, wire offset $\left(\mathrm{W}_{\text {off }}\right)$, water pressure (WP), servo feed (SF), wire material are employed as input process parameters while surface roughness (SR), material removal rate (MRR), kerf width, wire wear rate, surface integrity aspects are used as measures of process performance. Since last decade, a number of efforts have been made by research community to maximize the material removal rate, cutting speed, to minimize the surface roughness, kerf, wire wear rate and to improve the surface integrity aspects by different approaches as these factors can help to considerably enhance the economic benefits in WEDM.

Pulse-on time is the duration during which current is allowed to flow per cycle; the EDM operation is effectively done during this time. Mathew et al. (2014) reported that pulse-on time has significant effect on MRR and surface quality of machined surface and concluded that MRR and surface roughness increase with increasing pulse-on time. Discharge energy increases with increasing pulse-on time resulting more heat to sink into the workpiece and thus higher value of MRR (Ramakrishnan and Karunamoorthy, 2005). However, increase in discharge energy leads to larger craters and thus poor surface finish (Tosun et al., 2003; Ozdemir and Ozek, 2005; Han et al., 2007). Huang et al. (2015) reported that material removal rate, electrode wear rate, and surface roughness increase with increasing pulse current and duration. Pulse-off time is the duration of time between two successive sparks when the discharge is turned off. It is the relaxation period rest required for reionization of the dielectric. This time also allows the molten material to solidify and to be washed out from the spark gap (Cabannes, 2010).

Pulse-off time mainly affects the stability of the cut. When pulse off time is shorter, the number of discharges within a given period becomes more. However, if the pulse off time is too small, the ejected workpiece debris will not be flushed away with the flow of dielectric and dielectric fluid will not be deionised (Jain et al., 2011); results into instability of the next spark (Garg et al., 2010). It is observed that with increase in pulse-off time, MRR as well as surface roughness decrease (Manjaiah et al., 2014).

Peak current represents the amount of power used in discharge machining. The current increases until it reaches a preset level during pulse-on duration and it is known as peak current. Higher is the peak current, larger the discharge energy. Therefore, the effects of peak current and pulse-on time are almost identical (Tarang, 1995; Boghenian et al., 2008). A higher discharge current leads to higher MRR, overcut, and surface roughness. In addition, it is observed that the depth of recast layer increases with increasing discharge energy and consequently the workpiece become hardened than parent metal (Hascalyk and Caydas, 2008). Moreover, very high peak current values lead to frequent wire breakage. Lodhi et al. (2014) observed that the surface roughness was influenced by pulse-on time followed by peak current and pulse-off time. This finding is in accordance with the finding of Patel et al. (2013). They reported that pulse-on time is the most effective parameter for MRR followed by peak current and pulse-off time. 
Spark gap voltage is the reference voltage for actual gap voltage. Higher the servo reference voltage longer is the discharge waiting time. In order to obtain longer discharge waiting time, cutting speed need to be reduced. This leads to a wider discharge gap resulting in more stable discharge conditions and thus, better surface accuracy (Tarang, 1995). Smaller value of spark gap voltage narrows down the spark gap, which leads to more number of sparks per unit time. It speeds up the machining rate but the state of machining at the gap become unstable and frequent wire breakage can be experienced. Shichun et al. (2009) described that the open voltage not only determines the breakdown distance but also affects the wire vibration in the process, and it is demonstrated to be a key factor to influence the kerf width in micro-WEDM. Prakash et al. (2013) concluded that gap voltage is the most influencing parameter for MRR. In 2014, Manjaiah et al. (2015) investigated that servo voltage is having significant contributions in maximizing MRR and minimizing surface roughness during WEDM machining of Ti50Ni50-xCux alloy using both brass wire and zinc coated brass wires.

Wire feed is the rate at which wire is fed continuously for sparking. Kuriakose et al. (2004) observed that among the parameters namely time between two pulses, pulse duration, injection pressure, wire speed and wire tension, the time between two pulses has more influence on the surface characteristics. It is concluded by Patel et al. (2014) that wire feed has least effect on material removal rate and electrode wear rate. In WEDM, wire electrode contributes $70 \%$ of the machining cost (Dauw \& Beltrami, 1994). Thus, to achieve economical machining, lower wire feed rate is recommended. However, frequent wire breakage is observed when the wire feed is reduced below $5 \mathrm{~m} / \mathrm{min}$. Higher values of wire feed rate (above $6 \mathrm{~m} / \mathrm{min}$ ) are required for working with higher pulse power when the cutting rates are higher. Saini et al. (2014) observed that the MRR decreases with increasing wire feed rate and wire mechanical tension. The dielectric conductivity, maximum feed rate and injection pressure are found less significant for MRR.

The factors responsible for geometrical inaccuracy of the WEDM part are the various process forces acting on the wire causing it to depart from the programmed path. These forces include the mechanical forces produced by the pressure from the gas bubbles formed by plasma of the erosion mechanism. Thus, the tension is applied to the wire to keep it straight and un-deflected. Wire tension is the gram equivalent load with which the continuously fed wire is kept under tension so that it remains straight between the wire guides. A larger value of wire tension (above 10mu) causes frequent wire breakage owing to higher tensile forces. Small wire tension (less than $5 \mathrm{mu})$ tends to produce inaccurate parts as the wire become slack. It is reported by Liao et al. (2005) and Yuanyun (2007) that the kerf width varies with wire tension. Saini et al. (2014) observed that MRR decreases with the increase of wire tension.

Pulse peak voltage is established as an influencing factor for WEDM. As the pulse peak voltage increases, the pulse discharge energy also increases which in turn can improve the cutting rate.

The purpose of dielectric is to flush away the debris produced during machining and to keep the wire and work piece cool during machining. Effective flushing may also affect the surface roughness of the workpiece as well as influence 
crack density and recast layer (Wong et al., 1995). Higher flushing pressure is recommended for cutting with higher pulse power and jobs of larger thickness while it is observed that low flushing pressure is beneficial for thin jobs and trim cuts.

WEDM is a thermo-electric process and therefore the machined parts experience formation of heat-affected zone and recast layer. Goswami and Kumar, (2014) observed that recast layer increases with increase in pulse-on time and peak current. It is evident that the recast layer on the machined surface to be almost $100 \%$ thicker for the sample machined at high discharge energy level when compared to the sample machined at low discharge energy level. Zhang et al. (2015) reported that pulse-on time and pulse current have a significant effect on work harden layer while flushing pressure and feed rate also have a close relationship with surface integrity but are not the most important factors affecting the surface integrity. Chalisgaonkar and Kumar (2016) reported that large number of craters, debris and cracks are observed on zinc coated wire as compared to uncoated brass wire owing to development of higher intensity discharge. It is evident that thicker recast layer is developed after rough cut operation as compared to finish cut. Overall, uncoated wire produced better results for surface finish and recast layer. Use of lower wire offset in conjunction with lower setting of pulse-on time and peak current could be recommended for controlling the recast layer thickness. Tosun et al. (2003) conducted experimental investigation to study the effects process parameters on crater diameter and crater depth. It is obvious from the experimental outcome that increase in pulse duration, open circuit voltage, and wire speed increases the crater diameter and crater depth, whereas these factors decrease with increasing flushing pressure.

In present era of automation, the application of optimization and modelling techniques is finding ever increasing for controlling the manufacturing processes, as these techniques are equivalent to the incredible capability of human mind in learning uncertainties. A brief idea of various optimization and modelling techniques is available in references (Rajasekaran and Vijayalakshmi Pai, 2008; Chandrasekaran et al., 2010; Misra, 2009; Misra et al., 2013; Das and Misra, 2016). To the best knowledge of authors, Rajurkar and Wang (1993) are first who picked up research on modelling of WEDM process. They tried thermal modelling of the process to investigate the temperature distribution along wire electrode. It is evident that the highest temperature observed near to the exit of workpiece region. After that a number of researchers attempted optimization and modelling of WEDM process applying regression analysis (Tosun et al., 2003), Taguchi's orthogonal array (Manna and Bhattacharyya, 2006; Dabade and Karidkar, 2016), grey relation analysis (Chiang and Chong, 2006; Saedon et al., 2014), response surface methodology (Shandilya et al., 2011; Zhang et al., 2014, Sharma et al., 2013), artificial neural network (Sarkar et al., 2006), genetic algorithm (Sharma et al., 2015), fuzzy logic (Chalisgaonkar and Kumar, 2016), adaptive neuro-fuzzy inference system (Caydas et al., 2009), grey relational analysis coupled with genetic algorithm (Varun and Venkaiah, 2014), multi-objective evolutionary algorithm (Boopathi and Sivakumar, 2013), hybridized RSM and NSGA-II (Zhang et al., 2014), and finite element analysis (Sanchez et al., 2008; Plaza et al., 2009) to obtain the better insight of the process. 


\section{Summary}

In this book chapter a critical analysis of WEDM process has been carried out. On the basis of critical evaluation of the available literature following conclusions are summarised.

- WEDM process is a very precise manufacturing process and it is capable to produce complex shapes in any conductive material regardless its hardness.

- This technique can be successfully utilized for cutting, turning, step turning, taper turning, grinding and gear cutting operations and having huge potential to replace conventional processes.

- It is observed that in WEDM the input process parameters: pulse-on time, pulse-off time, servo voltage, peak current, wire feed rate, wire tension, wire offset, water pressure, servo feed, wire material are having significant influence on process performance characteristics namely surface roughness, material removal rate, kerf width, wire wear rate, surface integrity aspects, etc.

- A number of optimization and modelling techniques are attempted to improve the process capability.

Furthermore, the input and response parameters of WEDM for various materials are summarized in Table A1 for providing a guideline to the future users in deciding parametric setting for their job requirement.

\section{Future Scope}

From literature review it is obvious that a substantial amount of work on different aspects of WEDM has been carried out. It has been observed that most of the researchers concentrated on very few number of process parameters at a time to model and optimize various responses, which may not yield accurate optimal values for the process. Further, most of the researchers have given the importance to individual response modelling and its optimization. There is a lot of scope for effective multi objective optimization. Moreover, applicability of WEDM for cutting complex profiles is still at infant stage and has a long way to go. Therefore, the future work could consider following facets of WEDM process.

- WEDM process can be employed for other operations than cutting such as straight turning, step turning, taper turning, etc. In detail experimental investigation is also required to examine the applicability of WEDM for producing complex geometries such as gears, spline, curved surfaces, etc.

- WEDM processing of difficult-to-machine materials namely super alloys and shape memory alloys require proper attention.

- In present day scenario powdered products are emerged as a new dimension in materials technology. A vigorous study is required to investigate the process capability during WEDM of powdered products.

- The past research work primarily highlights the influences of input process parameters namely pulse-on time, pulse-off time, servo voltage, peak current, etc. on process performance characteristics. A comprehensive study is very essential to 
explore the effect of other input process parameters: dielectric, wire material, wire feed rate, wire tension, servo feed setting, threshold and cutting speed override.

- In-detail study of contribution of the individual input process parameters on process performance characteristics is lacking in literature.

- The mechanism of material removal and wire breakage in case of difficult-tomachine materials is not well established.

- The tribological and corrosional behaviour and surface integrity aspects of wire electric discharge machined parts need proper attention.

- Generally, the conventional WEDM is a stable process with good machining speed. However, high tool wear and considerable environmental impacts are the demerits of WEDM. On the other hand, dry WEDM is an unstable machining process with lower MRR and poor surface finish while this technique has advantage of minimum environmental impact. The drawbacks of wet and dry WEDM process can be eliminated in near-dry WEDM that yields better surface quality with considerable MRR, low tool wear, no chemical reaction of the dielectric fluid, less residual stress and minimum environmental impact.

\section{References}

Ali, M. Y., Mustafizul Karim, A. N., Adesta, E. Y. T., Ismail, A. F., Abdullah, A. A., \& Idris, M. N. (2010). Comparative study of conventional and micro WEDM based on machining of meso/micro sized spur gear. International Journal of Precision Engineering and Manufacturing, 11, 779-784.

Benedict, G.F. (1987). Electrical discharge wire cutting (EWDC), Non Traditional Manufacturing Processes, 234-235,

Boopathi, S., \& Sivakumar, K. (2013). Experimental investigation and parameter optimization of near-dry wire-cut electrical discharge machining using multiobjective evolutionary algorithm. International Journal of Advanced Manufacturing Technology, 67, 2639-2655.

Caydas, U., Hascalik, A., \& Ekici, S. (2009). An adaptive neuro-fuzzy inference system (ANFIS) model for wire-EDM. Expert Systems with Applications, 36, 61356139.

Chalisgaonkar, R., \& Kumar, J. (2016). Investigation of the machining parameters and integrity of the work and wire surfaces after finish cut WEDM of commercially pure titanium. J Braz. Soc. Mech. Sci. Eng, 883-911.

Chiang, K. T., \& Chang, F. P. (2006). Optimization of the WEDM process of particle-reinforced material with multiple performance characteristics using grey relational analysis. Journal of Materials Processing Technology, 180, 96-101.

David H., Dulebohn's G, Tracer controlled machining by electrically induced erosion, US Patent 3,614,372, filed 4 December 1969, issued 19 october 1971.

Dabade, U. A., \& Karidkar, S. S. (2016). Analysis of response variables in WEDM of inconel 718 using taguchi technique. Procedia CIRP, 41, 886-891.

Das, A., \& Misra, J. P. (2016). Modelling and parametric optimization of deposited layer thickness in electric discharge coating process. International Journal of Surface Science and Engineering, 10, 253-271. 
Dauw, D. F., \& Beltrarni, P. E. (1994). High-Precision Wire-EDM by Online Wire Positioning Control. Annals of the CIRP, 43, 193-197.

Garg R. K., Singh, K. K., Sachdeva A., Sharma S.V., Ojha K., \& Singh S. (2010). Review of research work in sinking EDM and WEDM on metal matrix composite materials. International Journal of Manufacturing Technology, 50, 611-625.

Garg, M. P., Jain, A., \& Bhushan, G. (2013). Multi-objective optimization of process parameters in wire electric discharge machining of Ti-6-2-4-2 Alloy. Arabian Journal for Science and Engineering, 39, 1465-1476.

Giridharan, A., \& Samuel, G. L. (2015). Modeling and analysis of crater formation during wire electrical discharge turning (WEDT) process. International Journal of Advanced Manufacturing Technology, 77,1229-1247.

Goswami, A., \& Kumar, J. (2014). Investigation of surface integrity, material removal rate and wire wear ratio for WEDM of Nimonic 80A alloy using GRA and Taguchi method. Engineering Science and Technology, an International Journal, 17, 173-184.

Guitrau E. The EDM Handbook. Cincinnati: Hanser Gardner Publications; 1997.

Gupta, K., Chaube, S. K., \& Jain, N. K. (2014). Exploring Wire-EDM for Manufacturing the High Quality Meso-gears. Procedia Materials Science, 5, 17551760.

Haddad, M. J., \& Tehrani, A. F. (2008). Investigation of cylindrical wire electrical discharge turning (CWEDT) of AISI D3 tool steel based on statistical analysis. Journal of Materials Processing Technology, 198, 77-85.

Han, F., Jiang, J., \& Yu, D. (2007). Influence of machining parameters on surface roughness in finish cut of WEDM. International Journal of Advanced Manufacturing Technology, 34(5-6), 538-546.

Hatami, S., Navid, M. S., \& Nyborg, L. (2012). Surface preparation of powder metallurgical tool steels by means of wire electrical discharge machining. Metallurgical and Materials Transactions, 43A, 3215-3226.

Huang, C. A., Hsu, C. C., \& Kuo, H. H. (2003). The surface characteristics of P/M high-speed steel (ASP 23) multi-cut with wire electrical discharge machine (WEDM). Journal of Materials Processing Technology, 140, 298-302.

Huang, T. S., Hsieh, S. F., Chen, S. L., Lin, M. H., Ou, S. F., \& Chang, W. T. (2015). Surface modification of TiNi-based shape memory alloys by dry electrical discharge machining. Journal of Materials Processing Technology, 221,279-284.

Intech EDM (1995). EDM Wire, A reference to understanding, selecting and using wire on wire-cut EDM machines. 2nd edition. U.S.A.

Jain, V.K. (2002) Advanced Machining Processes, Allied Publishers, Mumbai.

Jameson, E. C. (2001). Description and development of electrical discharge machining (EDM), Electrical Discharge Society of Manufacturing Engineers, Dearborn, Machigan, 16.

Klocke, F., Hensgen, L., Klink, A., Ehle, L., \& Schwedt, A. (2016). Structure and composition of the white layer in the wire-edm process. Procedia CIRP, 42, 673678.

Kuo, K. Y., Wu, K. L., Yang, C. K., \& Yan, B. H. (2015). Effect of adding SiC powder on surface quality of quartz glass microslit machined by ECDM. 
International Journal of Advanced Manufacturing Technology,78, 73-83.

Kuriakose S., \& Shunmugam M.S. (2004). Characteristics of wire-electro discharge machined Ti6Al4V surface.Materials Letters, 58, 2231-2237.

Liao, Y. S., Huang, J. T., \& Su, H. C. (1997). A study on the machining-parameters optimization of wire electrical discharge machining. Journal of Materials Processing Technology, 71, 487-493.

Liu, C. L., \& Esterling, D. (1997). Solid modelling of 4-axis wire EDM cut geometry, Comp Aided Des, 29, 803-810.

Liu, J. F., \& Guo, Y. B. (2015). Process capability of wire-edm of niti shape memory alloy at main cut and trim cut modes. Procedia Manufacturing, XXX, 904-914.

Lodhi, B. K., \& Agarwal, S. (2014). Optimization of machining parameters in WEDM of AISI D3 steel using taguchi technique. Procedia CIRP, 14, 194-199.

Mandal, A., Dixit, A. R., Das, A. K., \& Mandal, N. (2015). Modeling and optimization of machining nimonic c-263 super alloy using multi-cut strategy in WEDM. Materials and Manufacturing Processes, 6914.

Manjaiah, M., Narendranath, S., Basavarajappa, S., \& Gaitonde, V. N. (2014). Wire electric discharge machining characteristics of titanium nickel shape memory alloy. Transactions of Nonferrous Metals Society of China, 24, 3201-3209.

Manjaiah, M., Narendranath, S., Basavarajappa, S., \& Gaitonde, V. N. (2015). Effect of electrode material in wire electro discharge machining characteristics of Ti50Ni50-xCux shape memory alloy. Precision Engineering, 41, 68-77.

Manna, A., \& Bhattacharyya, B. (2006). Taguchi and gauss elimination method: a dual response approach for parametric optimization of cnc wire cut EDM of PRAlSiCMMC. International Journal of Advanced Manufacturing Technology, 28, 67-75.

Masuzawa, T., Fujino, M., Kobayashi, K., Suzuski, T., \& Kinoshita, N. (1985). Wire electro-discharge grinding for micro-machining, Ann. CIRP 34,431-434.

Ming, W., Zhang, Z., Zhang, G., Huang, Y., Guo, J., \& Chen, Y. (2014). Multiobjective optimization of 3d-surface topography of machining YG15 in WEDM. Materials and Manufacturing Processes, 29(5), 514-525.

Misra, J. P. (2009). Precision finishing of helical gears by electrochemical honing $(E C H)$ process. M.Tech Dissertation, Indian Institute of Technology Roorkee, India.

Misra, J. P., Jain, P. K., Dwivedi, D. K., \& Mehta, N. K. (2013). Mixture D-optimal design of electrolyte composition in $\mathrm{ECH}$ of bevel gears. Advanced Materials Research, 685, 347-351.

Mohammadi, H., \& Teharani, A. R. F. (2008). Evaluation of Surface Roughness and Material Removal Rate in CWEDM Using ANN. Power, 7, 11.

Nourbakhsh, F., Rajurkar, K. P., Malshe, A. P., \& Cao, J. (2013). Wire electrodischarge machining of titanium alloy. Procedia CIRP, 5, 13-18.

Ozdemir, N.,\&Ozek, C. (2006). An investigation on machinability of nodular cast iron by WEDM. Int J Adv Manuf Technol, 28, 869-872.

Patel, P. R., Patel, B. B.,\&Patel, V. A. (2013). Effect of machining parameters on surface roughnessfor 6063 al-tic $(5 \& 10 \%)$ metal matrix composite usingRSM. IJRET, 2, 65-71.

Plaza, S., Ortega, N., Sanchez, J. A., Pombo, I., \& Mendikute, A. (2009). Original 
models for the prediction of angular error in wire-EDM taper-cutting. International Journal of Advanced Manufacturing Technology, 44, 529-538.

Rajurkar, K.P.,\& Wang, W.M. (1993). Thermal modelling and online monitoring of Wire-EDM, Journal of Materials Processing Technology, 38, 417-430.

Rajyalakshmi, G., \& Venkata Ramaiah, P. (2013). Multiple process parameter optimization of wire electrical discharge machining on Inconel 825 using Taguchi grey relational analysis. International Journal of Advanced Manufacturing Technology, 69(5-8), 1249-1262.

Ramakrishnan, R., \& Karunamoorthy, L. (2006). Multi response optimization of wire EDM operations using robust design of experiments. International Journal of Advanced Manufacturing Technology, 29(1-2), 105-112.

Saedon, J. B., Jaafar, N., \& Azman, M. (2014). Multi-objective optimization of titanium alloy through orthogonal array and grey relational analysis in WEDM. Procedia Technology, 15, 833-841.

Saini, P. K.,\&Verma, M. (2014). Experimental Investigation of Wire-EDM Process Parameters on MRR of Ti-6al-4v Alloy. International Journal of Innovative Technology and Exploring Engineering (IJITEE), 4, 2278-3075.

Sanchez, J. A., Plaza, S., Ortega, N., Marcos, M., \& Albizuri, J. (2008). Experimental and numerical study of angular error in wire-EDM taper-cutting. International Journal of Machine Tools and Manufacture, 48, 1420-1428.

Sarkar, S., Mitra, S., \& Bhattacharyya, B. (2005). Parametric analysis and optimization of wire electrical discharge machining of $\gamma$-titanium aluminide alloy. Journal of Materials Processing Technology, 159, 286-294.

Sarkar, S., Mitra, S., \& Bhattacharyya, B. (2006). Parametric optimisation of wire electrical discharge machining of $\gamma$ titanium aluminide alloy through an artificial neural network model. International Journal of Advanced Manufacturing Technology, 27, 501-508.

Satishkumar, D., Kanthababu, M., Vajjiravelu, V., Anburaj, R., Sundarrajan, N. T., \& Arul, H. (2011). Investigation of wire electrical discharge machining characteristics of Al6063/SiCp composites. International Journal of Advanced Manufacturing Technology, 56(9-12), 975-986.

Shandilya, P., Jain, P. K., \& Jain, N. K. (2011). Neural Network Based Modeling in Wire Electric Discharge Machining of $\mathrm{SiC}_{\mathrm{p}} / 6061$ Aluminum Metal Matrix Composite. Advanced Materials Research, 383-390, 6679-6683.

Shandilya, P., Jain, P. K., \& Misra, J. P. (2010).Experimental investigation during wire electric discharge cutting of $\mathrm{SiC}_{\mathrm{p}} / 6061$ aluminium metal matrix composite. Annals of DAAAM for 2010 \& Proceedings of the 21st International DAAAM Symposium, 21(1), 1091-1092.

Sharma, N., Khanna, R., \& Gupta, R. D. (2015). WEDM process variables investigation for HSLA by response surface methodology and genetic algorithm. Engineering Science and Technology, an International Journal, 18, 171-177.

Sharma, N., Khanna, R., Gupta, R. D., \& Sharma, R. (2013). Modeling and multiresponse optimization on WEDM for HSLA by RSM. International Journal of Advanced Manufacturing Technology, 67, 2269-2281.

Shichun, D., Xuyang, C.,Dongbo, W., Zhenlong, W., Guanxin, C., \&Yuan, L. (2009). 
Analysis of kerf width in micro-WEDM. International Journal of Machine Tools \& Manufacture, 49, 788-792.

Singh, T., Misra, J. P., \& Singh, B. (2016). Experimental investigation of influence of process parameters on cutting rate during wedm of al 6063 alloy. Proc. of National Conference on Statistics And Analytical Methods In Production And Industrial Engineering, PEC University of Technology Chandigarh, 11-12.

Singh, T., Misra, J. P., \& Singh, B. (2016), Experimental investigation of influence of process parameters on MRR during WEDM of al6063 alloy. Materials Today:

Proceedings.

Shivade, A. S., \& Shinde, V. D. (2014). Multi-objective optimization in WEDM of D3 tool steel using integrated approach of Taguchi method \& Grey relational analysis. Journal of Industrial Engineering International, 10(4), 149-162.

Spedding, T. ., \& Wang, Z. (1997). Study on modeling of wire EDM process. Journal of Materials Processing Technology, 69, 18-28.

Subrahmanyam S. V., \& M. M. M. S. (2013). Evaluation of optimal parameters for machining with wire cut edm using grey-taguchi method. International Journal of Scientific and Reserach Publication, 3(3), 1-9.

Tarang, Y. S., Ma, S. C., \& Chung, L. K. (1995). Determination of optimal cutting parameters in wire electrical discharge machining.Int. J. Machine Tool Manuf., 35,1693-1701.

Tosun, N., \& Cogun, C. (2003). An investigation on wire wear in WEDM. Journal of Materials Processing Technology, 134, 273-278.

Tosun, N., Cogun, C., \& Inan, a. (2003). The Effect of Cutting Parameters on Workpiece Surface Roughness in Wire EDM. Machining Science and Technology, 7, 209-219.

Tosun, N., Cogun, C., \& Pihtili, H. (2003). The effect of cutting parameters on wire crater sizes in Wire EDM. International Journal of Advanced Manufacturing Technology, 21, 857-865.

Tosun, N., Cogun, C., \& Tosun, G. (2004). A study on kerf and material removal rate in wire electrical discharge machining based on Taguchi method. Journal of Materials Processing Technology, 152, 316-322.

Varun, A., \& Venkaiah, N. (2014). Simultaneous optimization of WEDM responses using grey relational analysis coupled with genetic algorithm while machining EN 353. International Journal of Advanced Manufacturing Technology, 76, 675-690.

Wong, Y. S., Lim, L. C.,\&Lee, L. C. (1995) Effects of flushing on Electro discharge machined surface.Journal of material processing technology, 48, 299-305.

Zhang, G., Zhang, Z., Ming, W., Guo, J., Huang, Y., \& Shao, X. (2014). The multiobjective optimization of medium-speed WEDM process parameters for machining SKD11 steel by the hybrid method of RSM and NSGA-II. International Journal of Advanced Manufacturing Technology, 70, 2097-2109.

Zhang, Z., Ming, W., Huang, H., Chen, Z., Xu, Z., Huang, Y., \& Zhang, G. (2015). Optimization of process parameters on surface integrity in wire electrical discharge machining of tungsten tool YG15. The International Journal of Advanced Manufacturing Technology. 


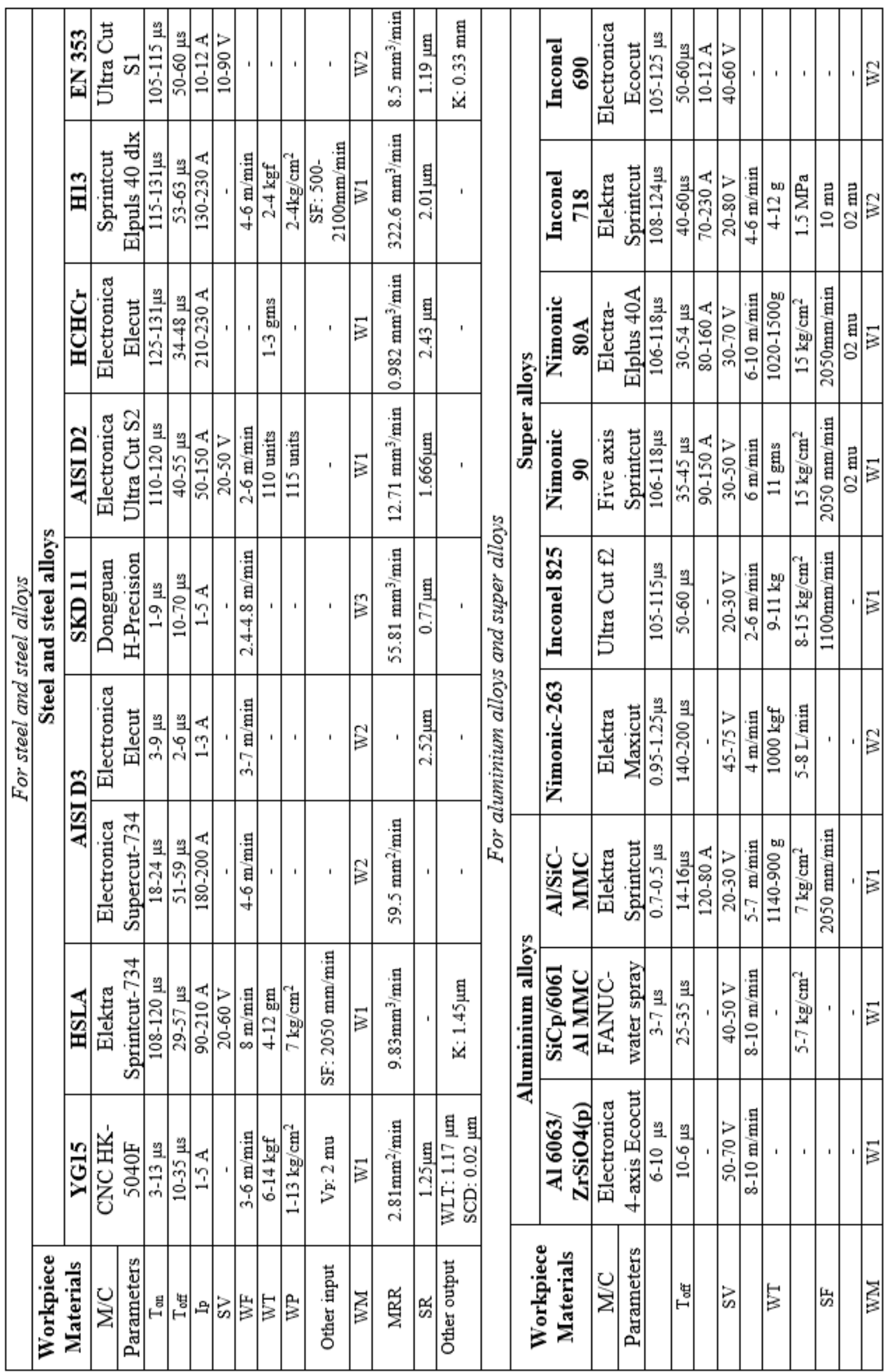




\section{Singh, B. \& Misra, J. P.: A Critical Review of Wire Electric Discharge Machining}

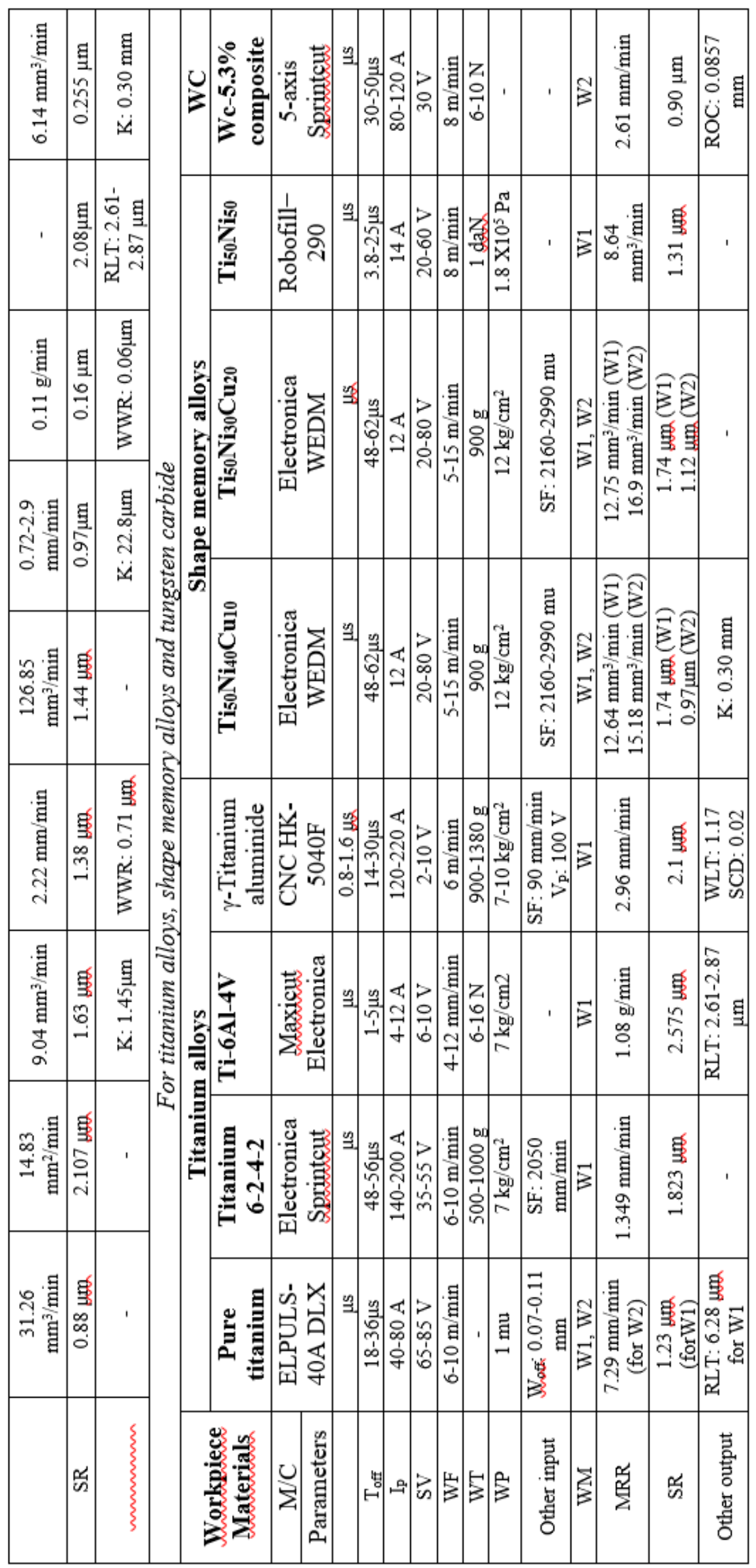

范之芳

氞芯芯市

范

$\varphi: 0 \frac{1}{0}$

की $Q \cdot \frac{\pi}{0}$

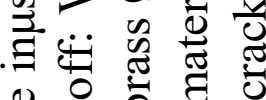

\& 3

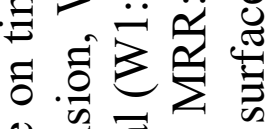

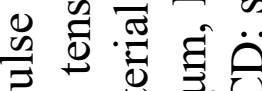

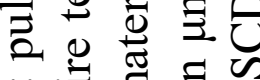

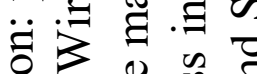

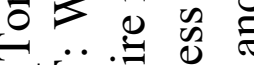

요요

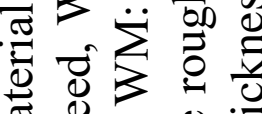

壱

言寻突

过芒需

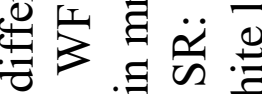

ठั

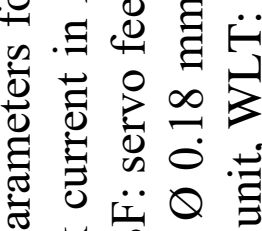

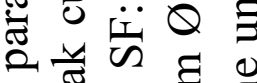

品 \&

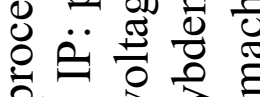

눈 > 궁.

‡

ڤี

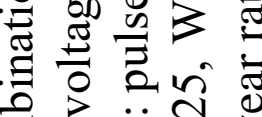

है

○ $>0$ Q

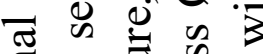

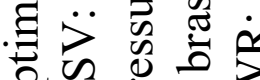

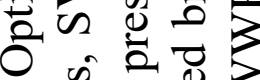

- $\mathrm{E} .0$

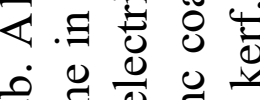

它 导产 